\title{
Acumulação de cobre e zinco em tecidos do feijoeiro em relação com o extraído do solo
}

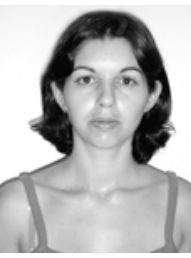

Tatiana Marsola1 , Mario Miyazawa² \& Marcos A. Pavan²

1 CENA-USP. CP 96 CEP 13400-970, Piracicaba, SP. E-mail: tmarsola@cena.usp.br (Foto)

2 Instituto Agronômico do Paraná. CP. 481. CEP 86001-970. Londrina, PR. E-mail: miyazawa@iapar.br

Protocolo 184 - 29/11/2002 - Aprovado em 2/4/2004

\begin{abstract}
Resumo: Avaliou-se, em casa de vegetação, o efeito de doses variando de $\mathrm{Cu}\left(0\right.$ a $\left.5,0 \mathrm{mmol} \mathrm{kg}^{-1}\right) \mathrm{e}$ de $\mathrm{Zn} \mathrm{(0} \mathrm{a} \mathrm{2,0} \mathrm{mmol} \mathrm{kg-1)} \mathrm{adicionados} \mathrm{em} \mathrm{um} \mathrm{Cambissolo} \mathrm{na} \mathrm{produção} \mathrm{de} \mathrm{matéria} \mathrm{seca} \mathrm{e} \mathrm{composição}$ mineral do feijoeiro. Adicionaram-se, separadamente, as doses de metais no solo e, após 30 dias de cultivo do feijoeiro, determinaram-se a matéria seca e os teores de $\mathrm{Cu}$ e $\mathrm{Zn}$ na parte aérea e raízes. Os teores dos metais nos tecidos das plantas foram correlacionados com os respectivos valores extraídos pelas soluções de $\mathrm{NH}_{4} \mathrm{OAc} 1,0 \mathrm{~mol} \mathrm{~L}^{-1} \mathrm{pH} 4,8$ e pH 7,0 e DTPA $5,0 \mathrm{mmol} \mathrm{L}^{-1} \mathrm{pH} 6,8$ e os teores de $\mathrm{Cu}$ da parte aérea e raiz aumentaram proporcionalmente às doses dos metais adicionadas ao solo. $\mathrm{O}$ acúmulo de $\mathrm{Cu}$ na raiz foi até 10 vezes superior ao da parte aérea, e aumentou com a dose de $\mathrm{Cu}$ até $5,0 \mathrm{mmol} \mathrm{kg}{ }^{-1}$ de solo. $\mathrm{O}$ feijoeiro não apresentou sintoma de fitotoxicidade e o teor de $\mathrm{Cu}$ da parte aérea não ultrapassou o nível considerado normal. O extrator DTPA apresentou a melhor correlação de Cu no solo com os teores da parte aérea e da raiz. Os teores de $\mathrm{Zn}$ dos tecidos de feijoeiro aumentaram com o acréscimo das doses do metal no solo. O teor de $\mathrm{Zn}$ na raiz, $330 \mathrm{mg}$ $\mathrm{kg}^{-1}$, foi superior ao da parte aérea da planta, $310 \mathrm{mg} \mathrm{kg}^{-1}$, mas não reduziu a produção de matéria seca nem apresentou sintomas de toxicidade nas folhas. As três soluções extratoras apresentaram alta correlação com os teores de $\mathrm{Zn}$ na parte aérea e na raiz do feijoeiro.
\end{abstract}

Palavras-chave: Phaseolus vulgaris, metais pesados, poluição do solo

\section{Accumulation of copper and zinc in the snap bean tissues in relation to that extracted from the soil}

\begin{abstract}
A greenhouse experiment was conducted to evaluate the effects of varying doses of $\mathrm{Cu}(\mathrm{O}$

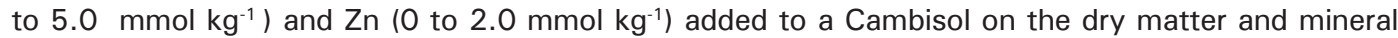
composition of snap beans. Separately the metals were added to the soil and after 30 days plant dry matter and $\mathrm{Cu}$ and $\mathrm{Zn}$ contents in aerial part and in the roots. The metal contents in the plant tissues were correlated with those present in the soil extracted with $1.0 \mathrm{~mol} \mathrm{~L}^{-1} \mathrm{NH}_{4} \mathrm{OAc} \mathrm{pH} 4.8$ and 7.0 , and $5.0 \mathrm{mmol} \mathrm{L}^{-1}$ DTPA pH 6.8. The $\mathrm{Cu}$ content in aerial part and roots increased in proportion to the doses added to soil. The accumulation of $\mathrm{Cu}$ in the roots was ten times greater than that found in the aerial part and increased with the $\mathrm{Cu}$ rates in soil up to $5.0 \mathrm{mmol} \mathrm{kg}^{-1}$. At application rate of 5.0 $\mathrm{mmol} \mathrm{kg} \mathrm{kg}^{-1}$ of soil, beans did not show phytotoxicity symptoms and the $\mathrm{Cu}$ concentration in the aerial part was below the normal level. The DTPA solution showed the best correlation of soil-Cu with aerial part- $\mathrm{Cu}$ and root- $\mathrm{Cu}$. The contents of $\mathrm{Zn}$ in the bean root tissues increased with increasing contents of metal in soil. The $\mathrm{Zn}$ concentration in the roots $\left(330 \mathrm{mg} \mathrm{kg}^{-1}\right)$ was greater than found in the aerial part $\left(310 \mathrm{mg} \mathrm{kg}^{-1}\right)$. But did not show toxicity symptoms in the leaves even in the highest $\mathrm{Zn}$ rates and did not reduce the dry matter production. The three soil-Zn extraction solutions showed high correlation with $\mathrm{Zn}$ concentration in the aerial part and in the roots of beans.
\end{abstract}

Key words: Phaseolus vulgaris, heavy metal, soil polution

\section{INTRODUÇÃO}

São denominados metais pesados todos aqueles que apresentam massa específica superior a $6 \mathrm{~g} \mathrm{~cm}^{-3}$, poluem o meio ambiente e podem provocar diferentes níveis de danos à biota. Os principais metais pesados são: $\mathrm{Ag}, \mathrm{Cd}, \mathrm{Co}, \mathrm{Cr}, \mathrm{Cu}$,
$\mathrm{Hg}, \mathrm{Ni}, \mathrm{Pb}, \mathrm{Sb}$, e $\mathrm{Zn}$, aos quais poderão, futuramente, ser incluídos outros metais, conforme a contaminação ambiental antropogênica. Os metais, pesados são encontrados naturalmente no solo em concentrações que variam de $\mu \mathrm{g}$ a $\mathrm{mg} \mathrm{kg}^{-1}$, as quais são inferiores às consideradas tóxicas para diferentes organismos vivos (Alloway, 1993). Alguns desses 
metais, como o $\mathrm{Co}$, o $\mathrm{Cu}$ e o $\mathrm{Zn}$, são nutrientes essenciais às plantas (Junqueira Neto, 1997); entretanto, o emprego de fungicidas, fertilizantes, esterco de animais, lixo urbano, lodo de esgoto no solo e a deposição de poeiras industriais, poderão elevar as concentrações de metais até níveis tóxicos.

Ainda que fertilizantes e corretivos possam ser fontes potenciais de contaminação no solo, a análise de amostras de 10 solos representativos do Estado do Paraná, em condições naturais e sob exploração agrícola, mostrou que os teores de metais pesados nos horizontes A e B dos diferentes ambientes não apresentaram diferenças (Souza et al., 1996); entretanto, em um solo com contínuas aplicações de fungicidas na lavoura de videira, durante 24 anos, a concentração de $\mathrm{Cu}$ aumentou de 310 para $516 \mathrm{mg} \mathrm{kg}^{-1}$ e no Zn foi de 138 para $185 \mathrm{mg} \mathrm{kg}^{-1}$ (Mattos \& Miyazawa, 1995). Pavan et al. (1994) também evidenciaram acúmulo de $\mathrm{Cu}$ no solo cultivado com cafeeiros tratados com fungicidas cúpricos por mais de 8 anos. Deluisa et al. (1996) observaram grande acúmulo de $\mathrm{Cu}\left(300 \mathrm{mg} \mathrm{kg}^{-1}\right)$ na superfície do solo cultivado com a videira na Itália.

Apesar da baixa utilização de lodo de esgoto, lixo urbano e lixo industrial no Brasil, ocorre crescente demanda para a aplicação desses materiais na agricultura e a aplicação de resíduos urbanos no solo ainda é uma das alternativas para o descarte desses materiais.

Os metais pesados sofrem várias reações químicas e bioquímicas no solo, as quais podem alterar suas solubilidades e mobilidades e, conseqüentemente, a disponibilidade e toxicidade para as biotas. A acidificação do solo geralmente aumenta a solubilidade de metais da forma livre, $\mathrm{M}^{\mathrm{n}+}$ (Basta \& Tabatabai, 1992; Reddy et al. 1995), que é espécie mais tóxica para biota. Por outro lado, os complexos organometálicos, $\mathrm{M}^{\mathrm{n}+} \mathrm{L}^{\mathrm{m}}$ - (em que, L - ligantes orgânicas), são solúveis em $\mathrm{pH}$ próximo de neutro, mas são menos tóxicos que na forma livre, $\mathrm{M}^{\mathrm{n}+}$ (Perdue et al. 1976; Emmerich et al., 1982; Dudley et al., 1987; Pohlman \& McColl, 1988 ).

O objetivo deste trabalho foi: a) determinar os níveis tóxicos de $\mathrm{Cu}$ e $\mathrm{Zn}$ para feijoeiro e seu efeito residual no solo; b) avaliar extratores de metais disponíveis do solo, e c) avaliar os efeitos de $\mathrm{Cu}$ e $\mathrm{Zn}$ na absorção de nutrientes pelo feijoeiro.

\section{MATERIAL E MÉTODOS}

Foi coletada amostra da camada de 0 a $20 \mathrm{~cm}$ de um Cambissolo, município de Curitiba, PR, secada ao ar e passada em peneira de $2 \mathrm{~mm}$. As características físicas e químicas originais do solo foram: $\mathrm{pH} 5,5\left(\mathrm{CaCl}_{2} 0,01 \mathrm{~mol} \mathrm{~L}^{-1}\right)$; $\mathrm{Ca} 67,0$ mmol kg-1 $\mathrm{Mg} 37,4$ mmol kg-1 C 35,3 $\mathrm{g} \mathrm{kg}^{-1}$; argila $510 \mathrm{~g} \mathrm{~kg}^{-1}$; areia $310 \mathrm{~g} \mathrm{~kg}^{-1}$ e silte $180 \mathrm{~g} \mathrm{~kg}^{-1}$. O experimento foi desenvolvido em casa de vegetação, em vasos de polietileno contendo $3,0 \mathrm{~kg}$ de material do solo, em um delineamento em blocos casualisados, com duas repetições que constaram das aplicações de quantidades crescentes de $\mathrm{CuCl}_{2}$ e $\mathrm{ZnCl}_{2}$ na ausência (sem esterco) e presença de $10 \mathrm{~g} \mathrm{~kg}^{-1}$ de esterco de aves (com esterco) aplicado ao solo. Os teores de nutrientes do esterco de poedeira estão apresentados na Tabela 1.

As doses empregadas, além da testemunha, foram 0,$1 ; 0,2$; 0,5; 1,0 e 2,0 mmol kg-1 de $\mathrm{ZnCl}_{2}$ e 0,$2 ; 0,5 ; 1,0 ; 2,0$ e 5,0 mmol kg-1 de $\mathrm{CuCl}_{2}$ em solo com e sem esterco de aves, sendo os metais
Tabela 1. Teores de nutrientes no esterco de aves

\begin{tabular}{|c|c|c|c|c|c|c|c|}
\hline $\mathrm{N}$ & $\mathrm{P}$ & $\mathrm{K}$ & $\mathrm{Ca}$ & $\mathrm{Mg}$ & $\mathrm{Cu}$ & $\mathrm{Mn}$ & B \\
\hline \multicolumn{5}{|c|}{$\mathrm{g} \mathrm{kg}^{-1}$} & \multicolumn{3}{|c|}{$\mathrm{mg} \mathrm{kg}^{-1}$} \\
\hline 31,3 & 32,0 & 23,0 & 102,6 & 9,2 & 289 & 291 & 48 \\
\hline
\end{tabular}

adicionados separadamente. Foram cultivadas, em cada vaso, quatro plantas de feijão IAPAR 57 (Phaseolus vulgaris); após 30 dias de emergência, a parte aérea e as raízes das plantas foram colhidas separadamente, secadas em estufa a $60{ }^{\circ} \mathrm{C}$, pesadas, moídas e passadas em peneira de $1 \mathrm{~mm}$; nessas amostras foram determinados N, P, K, Ca, Mg, Cu, Zn, Mn e B em espectrômetro de emissão atômica - ICP, Thermo Jarrel Ash ICAP 61E; K por fotometria de chama e $\mathrm{N}$ por espectrofotometria com azul de salicilato, após digestão sulfúrica (Miyazawa et al., 1984). Efetuaram-se três plantios do feijoeiro, em intervalos de quatro meses, para se avaliar o efeito residual dos metais nas plantas.

\section{Extração de cobre e zinco disponíveis do solo}

Após o corte das plantas do segundo plantio, coletaram-se amostras de solo para extração de cobre e zinco disponíveis. As soluções extratoras avaliadas, foram: $\mathrm{NH}_{4} \mathrm{OAc} 1,0 \mathrm{~mol} \mathrm{~L}^{-1}$ pH 4,8 e pH 7,0 e DTPA 5,0 mmol L $^{-1}$ pH 6,8 (TEA 15,0 g + DTPA $2,0 \mathrm{~g}+\mathrm{CaCl}_{2} \cdot 2 \mathrm{H}_{2} \mathrm{O} 1,5 \mathrm{~g}$ ). Para a extração de metais, transferiuse $1,0 \mathrm{~g}$ da amostra de solo (partículas menores que $1,0 \mathrm{~mm}$ ) para tubo de centrífuga de $50,0 \mathrm{~mL}$, adicionando-lhe $10,0 \mathrm{~mL}$ de solução extratora e se agitando durante uma hora (Adams \& Kissel, 1989; Beckett, 1989). Após decantação, as concentrações de $\mathrm{Cu}$ e $\mathrm{Zn}$ foram determinadas no sobrenadante, por emissão atômica (ICP); as quantidades de $\mathrm{Cu}$ e Zn extraídas foram correlacionadas com as concentrações do metal das plantas.

\section{Análise estatística}

Os dados foram analisados estatisticamente, através dos procedimentos do programa estatístico SAS (1989) admitindose o nível de significância $\mathrm{p} \leq 0,05$ para o coeficiente de determinação e para os estimadores dos parâmetros das equações de regressão.

\section{RESULTADOS E DISCUSSÃO}

\section{Absorção de metais pela planta}

$\mathrm{O}$ teor de $\mathrm{Cu}$ na parte aérea do feijoeiro, de três sucessivos cultivos no tratamento testemunha do sem esterco, variou de 3,3 a 4,9 $\mathrm{mg} \mathrm{kg}^{-1}$ e o do metal da testemunha com esterco, oscilou de 4,3 a 7,0 $\mathrm{mg} \mathrm{kg}^{-1}$. O ligeiro aumento no teor de $\mathrm{Cu}$ do feijoeiro com esterco está associado à presença deste metal no esterco (o esterco que contém $289 \mathrm{mg} \mathrm{kg}^{-1}$, equivalente à adição de $0,05 \mathrm{mmol} \mathrm{kg}^{-1}$ de $\mathrm{Cu}$ ). $\mathrm{O}$ teor do metal da parte aérea se correlacionou positivamente com as doses de $\mathrm{Cu}$ do solo sem esterco. A equação da curva do primeiro cultivo sem esterco foi: $\mathrm{y}=1,951 \mathrm{x}+5,388, \mathrm{R}^{2}=0,895$ (Figura 1 ).

A adição de $10 \mathrm{~g} \mathrm{~kg}^{-1}$ de esterco de aves promoveu maior produção de massa seca de feijoeiro em três sucessivos cultivos, entretanto, não foi observada diminuição na concentração de $\mathrm{Cu}$ no feijoeiro, mas esperava-se menor 


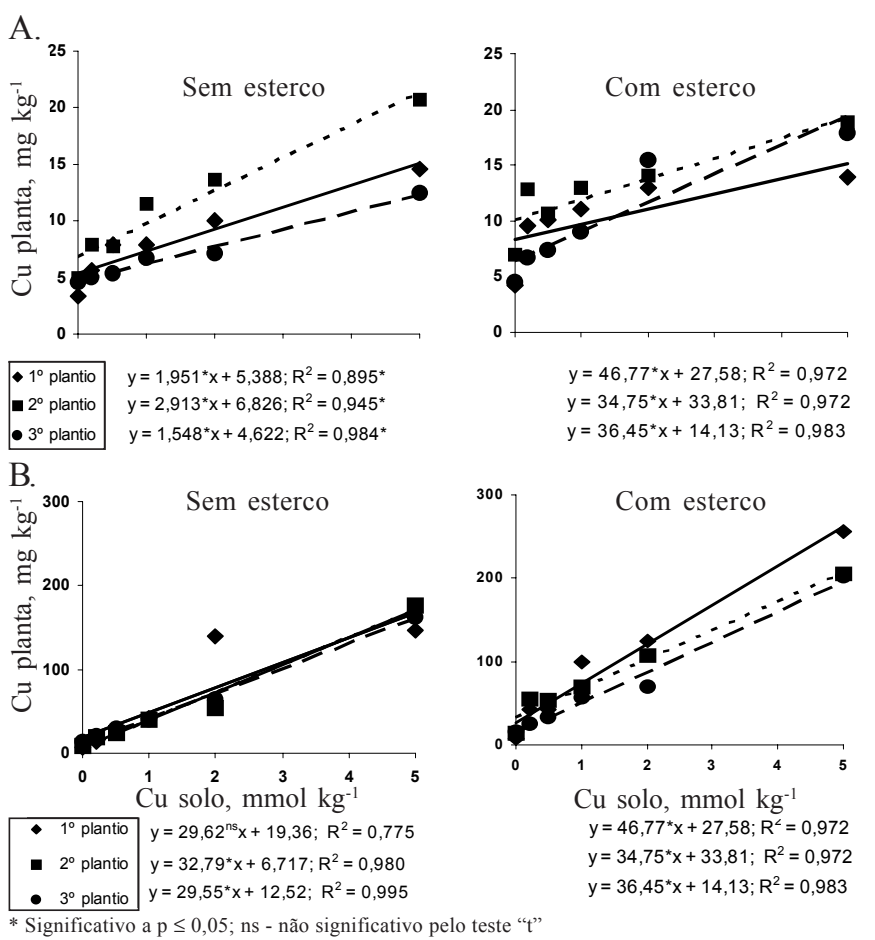

Figura 1. Efeito do Cu no acúmulo de metal na parte aérea (A) e raiz (B) do feijoeiro cultivado sem e com esterco de aves e respectivas equações das repetições de plantios

absorção do metal pela planta, devido à alta afinidade do metal com a matéria orgânica no esterco, que reduziria sua disponibilidade no solo. A adição de até 5,0 $\mathrm{mmol} \mathrm{kg}^{-1} \mathrm{de} \mathrm{Cu}^{2+}$ no Cambissolo não ultrapassou o limite normal do teor de $\mathrm{Cu}$ na folha do feijoeiro, que está entre 10 e $20 \mathrm{mg} \mathrm{kg}^{-1}$ (Junqueira Neto, 1997). A baixa absorção de Cu pela planta também foi observada por Sloan et al. (1997) em folhas de alface (Lactuca sativa L.), cultivada em solo contaminado com $\mathrm{Cu}$. A baixa absorção de $\mathrm{Cu}^{2+}$ pela planta pode ser atribuída à alta afinidade do metal com a matéria orgânica do tecido da raiz.

$\mathrm{O}$ teor de $\mathrm{Cu}$ na raiz do feijoeiro, cultivado em solo sem esterco, foi cerca de 3 a 10 vezes superior ao da parte aérea, enquanto a equação da correlação entre doses no solo e teor na raiz do primeiro cultivo foi: $y=29,62 x+19,36, R^{2}=0,775$. A adição de esterco no solo promoveu maior acúmulo do metal na raiz em todas as doses de $\mathrm{Cu}$, alcançando o maior valor (256 $\mathrm{mg} \mathrm{kg}^{-1}$ ), sendo a equação do primeiro cultivo: $\mathrm{y}=46,77 \mathrm{x}+$ $27,58, \mathrm{R}^{2}=0,972$. O maior acúmulo deste metal na raiz sugere que os ligantes orgânicos (L) do esterco de aves facilitaram a mobilidade do metal no solo pela formação de complexos $\mathrm{CuL}$ solúveis (Dudley et al., 1987). Vários estudos relatam o aumento da solubilidade dos metais polivalentes pela complexação com os ligantes orgânicos. Pohlman \& McColl (1988) e Perdue et al., (1976) observaram correlação direta entre teores de compostos orgânicos solúveis e de Al, Fe e Mn, em solução de solo da floresta. Dudley et al. (1987) evidenciaram complexos solúveis de organometálico de $\mathrm{Cu}$, $\mathrm{Ni}$ e $\mathrm{Zn}$ em solos tratados com lodo de esgoto. Reddy et al. (1995) estimaram que mais de $87 \%$ de $\mathrm{Cu}$ no extrato de água do solo a $\mathrm{pH}$ 5,4 se apresentam na forma orgânica.
A grande diferença entre as concentrações de $\mathrm{Cu}$ da parte aérea e da raiz sugere que a planta possui um mecanismo que reduz a difusão do cátion pelo interior do tecido, protegendoo da intoxicação. Devido a esta característica de acumular $\mathrm{Cu}$ na raiz, talvez este seja o tecido vegetal mais indicado para avaliar o grau de contaminação do solo por este metal.

O teor de Zn na parte aérea do feijoeiro cultivado em solos tratados com diferentes doses deste metal correlacionou-se positivamente com o teor no solo. A da curva do primeiro cultivo do solo sem esterco foi: $\mathrm{y}=145,6 \mathrm{x}+29,59, \mathrm{R}^{2}=0,986$, e seus valores variaram de 25,3 a $332 \mathrm{mg} \mathrm{kg}^{-1}$ (Figura 2). A equação para solos com esterco no primeiro cultivo, foi: $\mathrm{y}=78,57 \mathrm{x}+$ $45,32, \mathrm{R}^{2}=0,902$. Não se evidenciou efeito de substâncias orgânicas dos estercos de aves na absorção de $\mathrm{Zn}$, pelo feijoeiro. A adição de até $1,0 \mathrm{mmol} \mathrm{\textrm {kg } ^ { - 1 }}$ de $\mathrm{Zn}^{2+}$ no solo, com exceção do primeiro plantio, não ultrapassou valores normais no feijoeiro, que são de 30 a $100 \mathrm{mg} \mathrm{kg}^{-1}$ (Junqueira Neto, 1997), mas se observou uma sistemática diminuição no teor de Zn, na parte aérea da planta, pelos sucessivos cultivos em todas as doses no solo. A redução na absorção do Zn pela planta pode ser devida à lenta imobilização do metal no solo, complexação orgânica, precipitação e/ou hidrólise, e não pela extração do metal do solo pelos sucessivos cultivos de plantas, visto que a quantidade total de $\mathrm{Zn}$ extraído do solo pelo feijoeiro não ultrapassou a $1 \mathrm{mg} \mathrm{kg}^{-1}$.
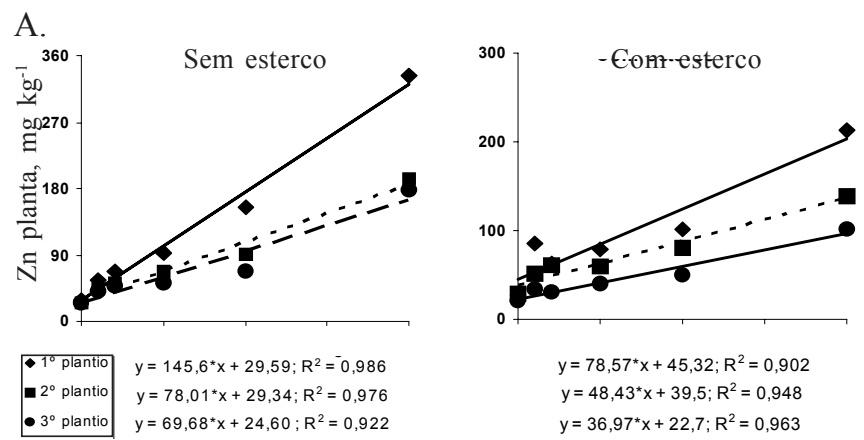

B.
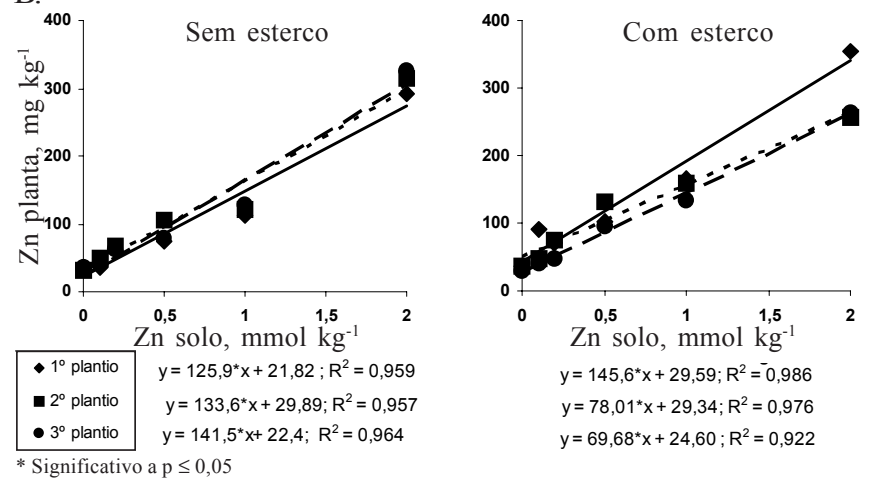

Figura 2. Efeito do Zn no acúmulo de metal na parte aérea (A) e raiz (B) do feijoeiro cultivado sem e com esterco de aves e respectivas equações das repetições de plantios

O teor de $\mathrm{Zn}$ da raiz do feijoeiro foi apenas ligeiramente superior ao da parte aérea, em todas as doses de metal; nos três sucessivos cultivos também não se observou efeito marcante do esterco de aves. A equação da correlação entre teor de $\mathrm{Zn}$ da raiz e as doses aplicadas no solo sem esterco no 
primeiro plantio, foi: $\mathrm{y}=125,9 \mathrm{x}+21,82, \mathrm{R}^{2}=0,959$ e no solo com esterco, de: $\mathrm{y}=148,6 \mathrm{x}+42,9, \mathrm{R}^{2}=0,967$.

Lavado et al. (2001) estudaram a adsorção de metais pesados e micronutrientes por plantas de milho, trigo e soja, comparando o cultivo convencional com o plantio direto e notaram que as raízes das plantas apresentaram maior quantidade de $\mathrm{Cu}$ e $\mathrm{Zn}$, comparando-as com as folhas e os grãos. As plantas de milho mostraram maior concentração de $\mathrm{Cu}$ na raiz $\left(48,58 \mathrm{mg} \mathrm{kg}^{-1}\right)$ enquanto as plantas de soja tiveram maior teor de $\mathrm{Zn}\left(64,73 \mathrm{mg} \mathrm{kg}^{-1}\right)$ quando cultivadas em plantio direto.

\section{Produção de massa seca}

A produção da massa seca do primeiro plantio de feijoeiro do controle sem esterco, foi 4,03 $\mathrm{g} \mathrm{vaso}^{-1} \mathrm{e}$, com esterco, foi de $11,05 \mathrm{~g} \mathrm{vaso}^{-1}$. A causa do maior crescimento dos feijoeiros dos solos com esterco se deve à maior quantidade de nutrientes do esterco fornecida para a planta. Apesar do $\mathrm{Cu}$ ser um micronutriente essencial às plantas, não se observou aumento na produção de massa seca do feijoeiro, mesmo para a menor dose $\left(0,2 \mathrm{mmol} \mathrm{kg}^{-1}\right)$ indicando que este metal no solo original estava em concentração adequada (Figura 3).

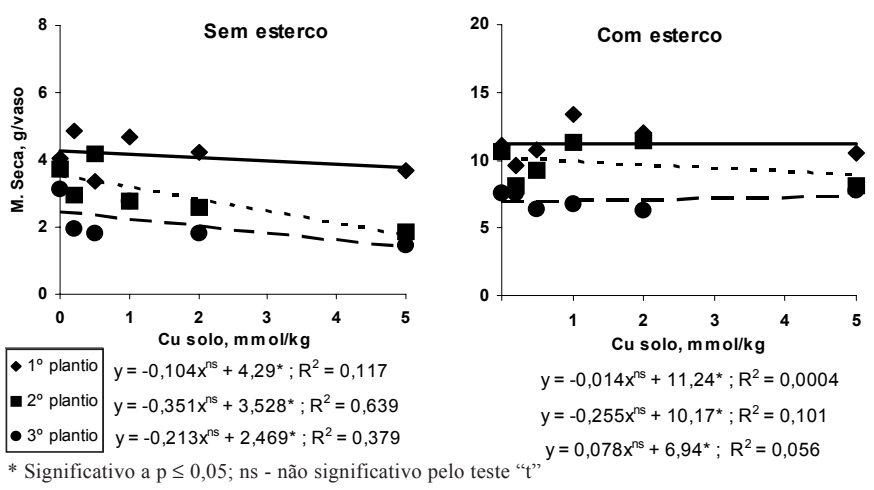

Figura 3. Efeito do $\mathrm{Cu}$ na produção de massa seca do feijoeiro cultivado sem e com esterco de aves e as respectivas equações das repetições de plantios

Estabeleceu-se, como critério de avaliação do nível tóxico do metal, a redução de $25 \%$ na produção de massa seca das plantas em relação ao tratamento controle. Com base neste

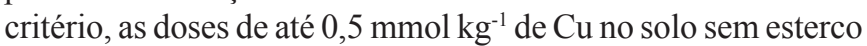
e até $5,0 \mathrm{mmol} \mathrm{kg}^{-1}$ no solo com esterco não causaram injúrias às plantas nos primeiro e segundo cultivos, porém no terceiro cultivo a dose de $0,2 \mathrm{mmol} \mathrm{kg}^{-1}$ de $\mathrm{Cu}$ no solo sem esterco, causou redução de $38 \%$ na produção de massa seca. Por outro lado, solos com esterco, até a maior dose de metal estudado $\left(5,0 \mathrm{mmol} \mathrm{kg}{ }^{-1}\right)$ não causou redução no crescimento da planta. Sugere-se que a adição do esterco no solo aumentou a matéria orgânica no solo e reduziu a disponibilidade do $\mathrm{Cu}^{2+}$.

A produção de massa seca da planta é um dos parâmetros utilizados na avaliação da toxicidade de uma substância; entretanto, estabelecer grau de toxicidade por apenas uma variável é um risco muito grande. O resultado deste experimento mostra que no solo sem esterco, dose de $1,0 \mathrm{mmol} \mathrm{kg}^{-1}$ de $\mathrm{Cu}$ no segundo plantio, causou redução de $25 \%$ na produção de massa seca, porém seu teor na parte aérea foi de $11,5 \mathrm{mg} \mathrm{kg}^{-1}$; este valor está dentro do intervalo normal, conforme estudos dos nutrientes do feijoeiro (Junqueira Neto, 1997).
A produção da massa seca do feijoeiro dos solos com $\mathrm{Zn}$ apresentou ligeira redução pelos sucessivos cultivos, tanto nos solos sem esterco como nos solos com esterco de aves. Esta redução ocorreu pelo consumo de nutrientes do solo, em razão de sucessivos cultivos de plantas (Figura 4) mas não se observou redução na produção de massa seca pela toxicidade da adição de até 2,0 mmol kg-1 de $\mathrm{Zn}$; tampouco, observou-se aumento de produção em doses menores, pela correção da deficiência do metal, cujo resultado mostra que este solo não apresentou deficiência de Zn para feijoeiro. Os teores de Zn na parte aérea da planta em dose máxima de $\mathrm{Zn}$, variaram de 101 (terceiro plantio no solo com esterco) a $332 \mathrm{mg} \mathrm{kg}^{-1}$ (primeiro plantio no solo sem esterco). Apesar do dobro do limite normal de $\mathrm{Zn}\left(100 \mathrm{mg} \mathrm{kg}^{-1}\right)$ as folhas apresentaram coloração normal e sem deformações.
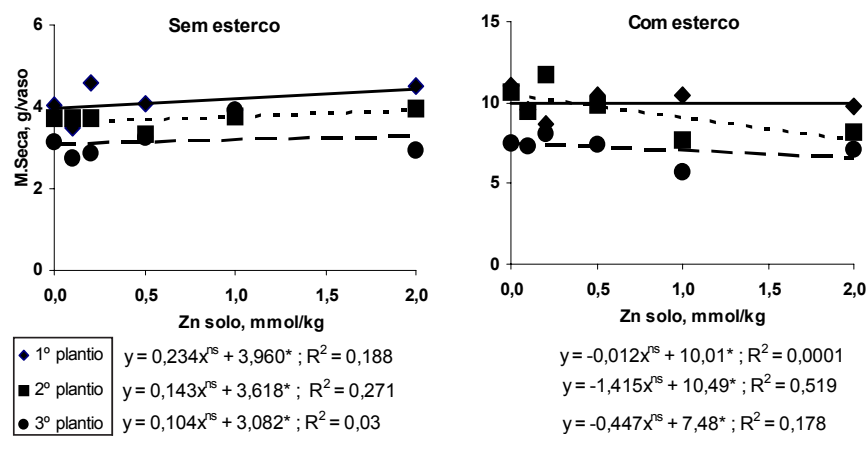

* Significativo a $\mathrm{p} \leq 0,05$; ns - não significativo pelo teste "t"

Figura 4. Efeito do Zn na produção de massa seca do feijoeiro cultivado sem e com esterco de aves e as respectivas equações das repetições de plantios

\section{Cobre e zinco disponíveis no solo}

A quantidade de $\mathrm{Cu}$ extraída do solo sem esterco com a solução de $\mathrm{NH}_{4} \mathrm{OAc} 1,0 \mathrm{~mol} \mathrm{~L}^{-1} \mathrm{pH} \mathrm{7,0}$ até doses de 5,0 mmol $\mathrm{kg}^{-1}$ de $\mathrm{Cu}$, variou de 0,0 a $5,48 \mathrm{mg} \mathrm{kg}^{-1}$ e as quantidades do solo com esterco foram maiores em todas as doses de $\mathrm{Cu}(0,06$ a 7,02 $\left.\mathrm{mg} \mathrm{kg}^{-1}\right)$. As equações das correlações entre teores de $\mathrm{Cu}$ da parte aérea e das raízes do feijoeiro com os extratores dos solos estão descritas na Tabela 2 .

A solução de $\mathrm{NH}_{4} \mathrm{OAc}$ 1,0 mol L-1 pH 4,8 extraiu do solo quantidades maiores de $\mathrm{Cu}$, em comparação com a solução $\mathrm{NH}_{4} \mathrm{OAc} \mathrm{pH} 7,0$. A mesma solução também extraiu quantidades maiores de $\mathrm{Cu}$ dos solos com esterco que dos solos sem esterco, cujos valores foram: 1,75 a 34,0 mg kg-1 e 1,11 a 32,6 $\mathrm{mg} \mathrm{kg}^{-1}$, respectivamente. A maior solubilidade do $\mathrm{Cu}$ dos solos com esterco sugere que os compostos orgânicos deste material formaram complexos CuL solúveis (Dudley et al., 1987).

Entre os extratores avaliados, a solução de DTPA solubilizou maior quantidade de $\mathrm{Cu}$, por se tratar de forte complexante de cátions polivalentes. As quantidades extraídas dos solos sem e com esterco, foram semelhantes, sendo 1,81 a 146,0 $\mathrm{mg} \mathrm{kg}^{-1} \mathrm{e}$ 2,51 a $127,0 \mathrm{mg} \mathrm{kg}^{-1}$, respectivamente. Entre os extratores avaliados, a solução de DTPA apresentou melhor correlação com os teores de $\mathrm{Cu}$ da parte aérea e da raiz de feijoeiro.

Todas as soluções utilizadas na extração de $\mathrm{Cu}$ disponível no solo apresentaram melhor correlação com os teores de $\mathrm{Cu}$ da raiz que da parte aérea da planta; portanto, a análise das raízes 
Tabela 2. Equações de correlação entre teor de $\mathrm{Cu}$ da parte aérea e raiz do feijoeiro com o extraído do solo por diferentes soluções

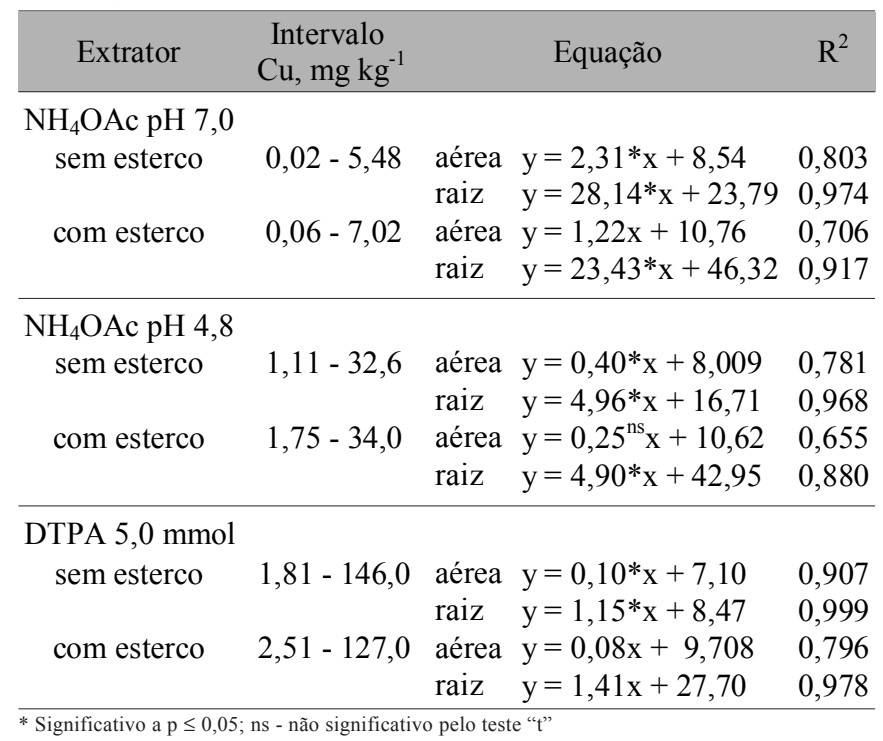

das plantas seria indicada na avaliação da contaminação do solo com $\mathrm{Cu}$; além disso, a maior concentração do metal na raiz facilita a observação na intensidade de contaminação do solo.

As quantidades de $\mathrm{Zn}$ dos solos sem esterco, quando adicionadas de 0 a 2,0 mmol kg-1 de metal com a solução de $\mathrm{NH}_{4} \mathrm{OAc} \mathrm{pH} 7,0$, variaram de 0,78 a 19,6 $\mathrm{mg} \mathrm{kg}^{-1}$. Os valores se correlacionaram positivamente com os teores do metal nas plantas e as equações de correlações entre as quantidades de Zn extraídas dos solos e os teores da parte aérea e da raiz do feijoeiro estão indicadas na Tabela 3 .

A adição de $10 \mathrm{~g} \mathrm{~kg}^{-1}$ de esterco de aves reduziu a quantidade de $\mathrm{Zn}$ solúvel em solução de $\mathrm{NH}_{4} \mathrm{OAc}$ pH 7,0 (0,79 a $\left.12,3 \mathrm{mg} \mathrm{kg}^{-1}\right)$. A redução da disponibilidade do metal no

Tabela 3. Equações de correlação entre teor de $\mathrm{Zn}$ da parte aérea e raiz do feijoeiro com o extraído do solo por diferentes soluções

\begin{tabular}{|c|c|c|c|c|}
\hline Extrator & $\begin{array}{c}\text { Intervalo } \\
\mathrm{Zn} \mathrm{mg} \mathrm{kg}^{-1}\end{array}$ & & Equação & $\mathrm{R}^{2}$ \\
\hline \multicolumn{5}{|l|}{$\mathrm{NH}_{4} \mathrm{OAc} \mathrm{pH} 7,0$} \\
\hline \multirow[t]{2}{*}{ sem esterco } & $0,78-19,6$ & aérea & $y=79,35^{\text {ns }} x-191,3$ & 0,650 \\
\hline & & raiz & $y=12,28 * x+27,92$ & 0,845 \\
\hline \multirow[t]{2}{*}{ com esterco } & $0,79-12,3$ & aérea & $y=8,27 * x+39,26$ & 0,942 \\
\hline & & raiz & $y=17,6^{*} x+51,60$ & 0,887 \\
\hline \multicolumn{5}{|c|}{$\mathrm{NH}_{4} \mathrm{OAc} \mathrm{pH} 4,8$} \\
\hline \multirow[t]{2}{*}{ sem esterco } & $5,88-143,0$ & aérea & $y=13,9 * x-167,7$ & 0,936 \\
\hline & & raiz & $y=1,93 * x+40,20$ & 0,970 \\
\hline \multirow[t]{2}{*}{ com esterco } & $5,67-137,0$ & aérea & $y=0,098 * x+42,47$ & 0,914 \\
\hline & & raiz & $y=1,54 * x+58,14$ & 0,886 \\
\hline \multirow{3}{*}{$\begin{array}{c}\text { DTPA } 5 \text { mmol } \\
\text { sem esterco }\end{array}$} & & & & \\
\hline & $3,55-104,0$ & aérea & $y=1,57 * x+25,51$ & 0,985 \\
\hline & & raiz & $y=2,68 * x+23,22$ & 0,969 \\
\hline \multirow[t]{2}{*}{ com esterco } & $3,37-112,0$ & aérea & $y=0,912 * x+39,12$ & 0,957 \\
\hline & & raiz & $y=1,96 * x+50,81$ & 0,916 \\
\hline
\end{tabular}

tratamento com adição de esterco se deu pela formação de complexos orgânicos ZnL dos estercos (Dudley et al., 1987).

A solução de $\mathrm{NH}_{4} \mathrm{OAc}$ pH 4,8 extraiu quantidades de $\mathrm{Zn}$ do solo muito superiores (cerca de 10 vezes) a $\mathrm{NH}_{4} \mathrm{OAc} \mathrm{pH}$ 7,0. As quantidades suprimidas aos solos sem e com esterco, foram semelhantes, sendo 5,88 a 143,0 $\mathrm{mg} \mathrm{kg}^{-1}$ e 5,67 a 137,0 $\mathrm{mg} \mathrm{kg}^{-1}$, respectivamente. Não se constatou efeito da matéria orgânica do esterco na disponibilidade de $\mathrm{Zn}$.

A solubilidade de $\mathrm{Zn}$ do solo em solução de DTPA foi semelhante a $\mathrm{NH}_{4} \mathrm{OAc}$ pH 4,8 onde também não se observou efeito da matéria orgânica do esterco de aves sobre a disponibilidade do metal.

A ordem da quantidade de $\mathrm{Zn}$ extraída pelas soluções avaliadas foi: $\mathrm{NH}_{4} \mathrm{OAc} \mathrm{pH} 7,0<\mathrm{NH}_{4} \mathrm{OAc} \mathrm{pH} 4,5 \cong$ DTPA 5,0 mmol, sendo que as soluções apresentaram correlações semelhantes aos teores de $\mathrm{Zn}$ da parte aérea e raiz das plantas.

\section{Efeito do Cu e Zn na absorção de nutrientes pela planta}

Os teores dos nutrientes $\mathrm{N}, \mathrm{P}, \mathrm{K}, \mathrm{Ca}$ e $\mathrm{Mg}$ da parte aérea do feijoeiro foram maiores quando cultivados em solo com esterco de aves, devido ao fornecimento desses nutrientes pelo esterco de aves às plantas; entretanto, não foram observadas alterações nas concentrações de N, P, Ca, Mg, Zn e B, exceto de Mn e K da parte aérea das plantas, quando adicionados até 5,0 mmol kg-1 de $\mathrm{Cu}^{2+}$ em solos sem e com de esterco de aves (Tabela 4). O teor de Mn no feijoeiro cultivado em solo com esterco foi maior que sem esterco.

Sendo o $\mathrm{Mn}^{2+}$ uma das espécies mais abundantes no solo e apresentando alta afinidade com a matéria orgânica, esperavase diminuição na absorção pela planta com a adição de esterco no solo. Este resultado indica que a adição de esterco aumenta a disponibilidade de $\mathrm{Mn}$, talvez na forma de complexos $\mathrm{MnL}$ (Perdue et al., 1976).

O teor de $\mathrm{Mn}$ da parte aérea da planta se correlacionou negativamente com as doses de $\mathrm{Cu}$ do solo sem esterco, cuja equação foi: $\mathrm{y}=-11,35 \mathrm{x}+178, \mathrm{R}^{2}=0,749$. Sugere-se que o $\mathrm{Cu}$

Tabela 4. Efeito das doses de $\mathrm{Cu}$ do solo no teor de nutrientes da parte aérea do feijoeiro no $1^{\circ}$ cultivo

\begin{tabular}{|c|c|c|c|c|c|c|c|c|c|}
\hline \multirow{2}{*}{ Esterco } & \multirow{2}{*}{$\begin{array}{c}\mathrm{Cu} \\
10^{-3} \mathrm{M}\end{array}$} & $\mathrm{N}$ & $\mathrm{P}$ & K & $\mathrm{Ca}$ & $\mathrm{Mg}$ & $\mathrm{Zn}$ & $\mathrm{Mn}$ & B \\
\hline & & \multicolumn{5}{|c|}{$\mathrm{g} \mathrm{kg}^{-1}$} & \multicolumn{3}{|c|}{$\mathrm{mg} \mathrm{kg}^{-1}$} \\
\hline \multirow{6}{*}{$\begin{array}{l}\text { sem } \\
\text { esterco }\end{array}$} & 0 & 39,5 & 1,0 & 23,1 & 21,5 & 7,5 & 28,3 & 171 & 42,6 \\
\hline & 0,2 & 28,1 & 0,9 & 18,1 & 17,3 & 6,6 & 18,6 & 194 & 38,1 \\
\hline & 0,5 & 38,1 & 1,1 & 28,8 & 19,1 & 5,8 & 24,5 & 180 & 43,7 \\
\hline & 1,0 & 25,2 & 0,9 & 17,0 & 16,7 & 5,8 & 18,9 & 154 & 37,3 \\
\hline & 2,0 & 34,4 & 0,9 & 21,2 & 18,2 & 6,4 & 20,8 & 144 & 38,6 \\
\hline & 5,0 & 34,3 & 0,9 & 20,1 & 16,0 & 6,2 & 18,8 & 127 & 34,0 \\
\hline \multicolumn{2}{|c|}{ Equação linear } & $\mathrm{ns}$ & ns & ns & $\mathrm{ns}$ & ns & ns & $*$ & ns \\
\hline \multicolumn{2}{|c|}{ Equação quadrática } & ns & ns & ns & ns & ns & ns & ns & ns \\
\hline \multirow{6}{*}{$\begin{array}{l}\text { com } \\
\text { esterco }\end{array}$} & 0 & 48,0 & 2,8 & 35,0 & 26,0 & 7,6 & 28,1 & 288 & 35,0 \\
\hline & 0,2 & 44,6 & 2,7 & 36,6 & 22,4 & 7,2 & 24,9 & 210 & 33,4 \\
\hline & 0,5 & 45,6 & 2,8 & 35,2 & 23,6 & 6,5 & 26,9 & 215 & 32,8 \\
\hline & 1,0 & 48,3 & 2,8 & 33,9 & 22,7 & 6,6 & 26,2 & 234 & 34,5 \\
\hline & 2,0 & 48,5 & 3,3 & 32,6 & 27,0 & 7,6 & 29,7 & 295 & 36,5 \\
\hline & 5,0 & 44,4 & 2,3 & 30,1 & 25,5 & 7,8 & 25,4 & 290 & 36,4 \\
\hline \multirow{2}{*}{\multicolumn{2}{|c|}{$\begin{array}{l}\text { Equação linear } \\
\text { Equação quadrática }\end{array}$}} & $\mathrm{ns}$ & ns & * & ns & ns & ns & ns & ns \\
\hline & & $\mathrm{ns}$ & ns & $\mathrm{ns}$ & $\mathrm{ns}$ & ns & $\mathrm{ns}$ & $\mathrm{ns}$ & $\mathrm{ns}$ \\
\hline
\end{tabular}


apresenta efeito antagônico na absorção de Mn pela planta. A concentração do $\mathrm{K}$ da parte aérea da planta cultivada no solo com esterco, também diminui com aumento da dose de $\mathrm{Cu}$; a equação foi: $\mathrm{y}=-1,15 \mathrm{x}+35,6, \mathrm{R}^{2}=0,895$. $\mathrm{O} \mathrm{K}^{+}$, por ser um cátion monovalente, não deve competir com o $\mathrm{Cu}^{2+}$ na absorção pela planta, mas, neste experimento, apresentou efeito negativo do $\mathrm{Cu}^{2+}$ sobre $\mathrm{K}^{+}$.

Os teores de P, K, Ca, Mg, Zn, Mn e B da raiz da planta também não foram alterados pelo aumento das doses de $\mathrm{Cu}$ no solo sem e com esterco (Tabela 5).

Os teores de todos os nutrientes da parte aérea do feijoeiro até a dose de 2,0 mmol $\mathrm{kg}^{-1}$ de $\mathrm{Zn}$ foram semelhantes com a adição de $\mathrm{Cu}$ no solo (Tabela 6). Os teores foram maiores em solo com esterco que em solos sem esterco, devido à

Tabela 5. Efeito das doses de $\mathrm{Cu}$ do solo no acúmulo de nutrientes da raiz do feijoeiro

\begin{tabular}{|c|c|c|c|c|c|c|c|c|}
\hline \multirow{2}{*}{ Esterco } & \multirow{2}{*}{$\begin{array}{c}\mathrm{Cu} \\
10^{-3} \mathrm{M}\end{array}$} & $\mathrm{P}$ & $\mathrm{K}$ & $\mathrm{Ca}$ & $\mathrm{Mg}$ & $\mathrm{Zn}$ & $\mathrm{Mn}$ & B \\
\hline & & \multicolumn{4}{|c|}{$\mathrm{g} \mathrm{kg}^{-1}$} & \multicolumn{3}{|c|}{$\mathrm{mg} \mathrm{kg}^{-1}$} \\
\hline \multirow{6}{*}{$\begin{array}{c}\text { sem } \\
\text { esterco }\end{array}$} & 0 & 0,7 & 5,5 & 8,8 & 2,5 & 33,2 & 196 & 69,3 \\
\hline & 0,2 & 0,9 & 10,5 & 9,1 & 4,4 & 21,3 & 188 & 42,7 \\
\hline & 0,5 & 1,0 & 18,1 & 11,1 & 3,3 & 30,3 & 198 & 63,0 \\
\hline & 1,0 & 0,9 & 8,5 & 10,3 & 4,6 & 31,0 & 218 & 47,1 \\
\hline & 2,0 & 0,6 & 3,6 & 9,6 & 2,6 & 24,0 & 177 & 60,0 \\
\hline & & 0,6 & 2,7 & 10,0 & 2,5 & 25,9 & 189 & 61,1 \\
\hline \multirow{2}{*}{\multicolumn{2}{|c|}{$\begin{array}{l}\text { Equação Linear } \\
\text { Equação Quadrática }\end{array}$}} & $\mathrm{ns}$ & $\mathrm{ns}$ & ns & $\mathrm{ns}$ & ns & $\mathrm{ns}$ & ns \\
\hline & & ns & ns & ns & ns & ns & ns & ns \\
\hline \multirow{6}{*}{$\begin{array}{c}\text { com } \\
\text { esterco }\end{array}$} & 0 & 1,2 & 15,5 & 11,2 & 2,5 & 37,0 & 285 & 55,2 \\
\hline & 0,2 & 2,2 & 10,5 & 13,5 & 3,1 & 39,6 & 336 & 42,4 \\
\hline & 0,5 & 1,5 & 11,5 & 12,4 & 2,5 & 33,9 & 345 & 40,8 \\
\hline & 1,0 & 2,1 & 10,6 & 16,2 & 3,1 & 45,1 & 413 & 43,3 \\
\hline & 2,0 & 2,0 & 15,2 & 13,7 & 3,5 & 39,1 & 286 & 44,6 \\
\hline & 5,0 & 1,8 & 11,6 & 13,8 & 3,6 & 42,8 & 309 & 35,7 \\
\hline \multicolumn{2}{|c|}{ Equação Linear } & ns & ns & ns & $\mathrm{ns}$ & ns & $\mathrm{ns}$ & $\mathrm{ns}$ \\
\hline \multicolumn{2}{|c|}{ Equação Quadrática } & ns & ns & ns & ns & ns & ns & ns \\
\hline
\end{tabular}

* Significativo a $\mathrm{p} \leq 0,05$; ns - não significativo

Tabela 6. Efeito das doses de $\mathrm{Zn}$ do solo no acúmulo de nutrientes na parte aérea do feijoeiro

\begin{tabular}{|c|c|c|c|c|c|c|c|c|c|}
\hline \multirow{2}{*}{ Esterco } & \multirow{2}{*}{$\begin{array}{c}\mathrm{Zn} \\
10^{-3} \mathrm{M}\end{array}$} & $\mathrm{N}$ & $\mathrm{P}$ & $\mathrm{K}$ & $\mathrm{Ca}$ & $\mathrm{Mg}$ & $\mathrm{Cu}$ & $\mathrm{Mn}$ & B \\
\hline & & \multicolumn{4}{|c|}{$\mathrm{g} \mathrm{kg}^{-1}$} & \multicolumn{4}{|c|}{$\mathrm{mg} \mathrm{kg}^{-1}$} \\
\hline \multirow{6}{*}{$\begin{array}{c}\text { sem } \\
\text { esterco }\end{array}$} & 0 & & 1,0 & 23,1 & 21,5 & 7,5 & 4,9 & 171 & 42,6 \\
\hline & 0,1 & 41,0 & 1,3 & 27,6 & 22,1 & 6,8 & 5,6 & 195 & 44,4 \\
\hline & 0,2 & 37,1 & 1,0 & 23,9 & 17,8 & 5,6 & 4,8 & 136 & 39,0 \\
\hline & 0,5 & 44,5 & 1,5 & 25,1 & 16,7 & 5,0 & 6,0 & 143 & 36,3 \\
\hline & 1,0 & 43,6 & 1,4 & 31 & 19,1 & 6,0 & 6,1 & 117 & 40,6 \\
\hline & & & 1,4 & 33,9 & 21,6 & 6,8 & 6,9 & 137 & 43,4 \\
\hline \multicolumn{2}{|c|}{ Equação Linear } & ns & ns & * & ns & ns & ns & ns & ns \\
\hline \multicolumn{2}{|c|}{ Equação Quadrática } & ns & ns & ns & $\mathrm{ns}$ & ns & $\mathrm{ns}$ & $\mathrm{ns}$ & $\mathrm{ns}$ \\
\hline \multirow{6}{*}{$\begin{array}{c}\text { com } \\
\text { esterco }\end{array}$} & 0 & 48,0 & 2,8 & 35,0 & 26,0 & 7,6 & 7,2 & 288 & 35,0 \\
\hline & 0,1 & & 3,0 & 35,2 & & 7,4 & 7,7 & 237 & 34,2 \\
\hline & 0,2 & 45,2 & 2,8 & 36,6 & 24,2 & 6,9 & 7,3 & 222 & 33,1 \\
\hline & 0,5 & 45,0 & 2,9 & 35,2 & 25,1 & 7,6 & 7,8 & 209 & 32,9 \\
\hline & 1,0 & 48,0 & 3,3 & 33,9 & 22,6 & 6,2 & 8,9 & 233 & 36,8 \\
\hline & 2,0 & 49,6 & 3,1 & 35,2 & 23,3 & 6,9 & 8,0 & 261 & 41,4 \\
\hline \multirow{2}{*}{\multicolumn{2}{|c|}{$\begin{array}{l}\text { Equação Linear } \\
\text { Equação Quadrática }\end{array}$}} & $\mathrm{ns}$ & ns & ns & $\mathrm{ns}$ & ns & ns & ns & ns \\
\hline & & ns & ns & ns & ns & ns & ns & ns & $\mathrm{ns}$ \\
\hline
\end{tabular}

* Significativo a $\mathrm{p} \leq 0,05$, ns - não significativo composição deste material (esterco de aves), rico em nutrientes; entretanto, não foi observado efeito sinérgico ou antagônico até a dose de 2,0 mmol kg-1 de $\mathrm{Zn}$ sobre a absorção de nutrientes, exceto de $\mathrm{Mn}$. O teor de $\mathrm{K}$ da planta cultivada em solo sem esterco, correlacionou-se positivamente com as doses de $\mathrm{Zn}$ no solo, mostrando efeito sinérgico sobre $\mathrm{K}$, em que a equação da correlação foi: $\mathrm{y}=5,10 \mathrm{x}+24,3, \mathrm{R}^{2}=0,805$.

Os teores dos nutrientes $\mathrm{P}, \mathrm{Ca}, \mathrm{Mg}, \mathrm{Cu}, \mathrm{Mn}$ e $\mathrm{B}$ na raiz da planta não foram alterados pela adição de até $2,0 \mathrm{mmol} \mathrm{kg} \mathrm{me}^{-1} \mathrm{de}$ $\mathrm{Zn}$ ao solo (Tabela 7). O potássio foi o único elemento que aumentou o teor na raiz, pelo acréscimo de Zn no solo sem esterco, enquanto a equação da correlação foi: $y=-41,2 x^{2}+104 x+2,54$, $\mathrm{R}^{2}=0,990$, cujo fato é atribuído ao acúmulo de $\mathrm{Zn}$ na raiz das plantas, causando aumento de K na superfície externa do tecido.

Tabela 7. Efeito das doses de Zn do solo no acúmulo de nutrientes na raiz do feijoeiro

\begin{tabular}{|c|c|c|c|c|c|c|c|c|}
\hline \multirow{2}{*}{ Esterco } & \multirow{2}{*}{$\underset{10^{-3} \mathrm{M}}{\mathrm{Zn}}$} & $\mathrm{P}$ & $\mathrm{K}$ & $\mathrm{Ca}$ & $\mathrm{Mg}$ & $\mathrm{Cu}$ & $\mathrm{Mn}$ & B \\
\hline & & \multicolumn{4}{|c|}{$\mathrm{g} \mathrm{kg}^{-1}$} & \multicolumn{3}{|c|}{$\mathrm{mg} \mathrm{kg}^{-1}$} \\
\hline \multirow{6}{*}{$\begin{array}{c}\text { sem } \\
\text { esterco }\end{array}$} & 0 & 0,7 & 5,5 & 8,8 & 2,5 & 6,6 & 196 & 69,3 \\
\hline & 0,1 & 0,8 & 8,5 & 9,9 & 3,1 & 7,9 & 183 & 48,2 \\
\hline & 0,2 & 0,8 & 21,5 & 10,0 & 3,6 & 7,2 & 192 & 50,6 \\
\hline & 0,5 & 0,5 & 46,0 & 10,3 & 2,4 & 7,4 & 190 & 59,2 \\
\hline & 1,0 & 0,5 & 65,0 & 10,4 & 2,3 & 7,6 & 194 & 50,7 \\
\hline & 2,0 & 0,5 & 46,0 & 9,4 & 2,6 & 7,8 & 224 & 67,4 \\
\hline \multicolumn{2}{|c|}{ Equação Linear } & ns & $\mathrm{ns}$ & ns & ns & $\mathrm{ns}$ & ns & ns \\
\hline \multicolumn{2}{|c|}{ Equação Quadrática } & ns & $\mathrm{ns}$ & $\mathrm{ns}$ & ns & $\mathrm{ns}$ & ns & $\mathrm{ns}$ \\
\hline \multirow{6}{*}{$\begin{array}{c}\text { com } \\
\text { esterco }\end{array}$} & 0 & 1,2 & 5,5 & 11,2 & 2,5 & 12,6 & 285 & 55,2 \\
\hline & 0,1 & 2,5 & 23,9 & 11,5 & 4,3 & 15,2 & 231 & 43,5 \\
\hline & 0,2 & 1,7 & 13,7 & 11,8 & 3,3 & 15,4 & 205 & 42,7 \\
\hline & 0,5 & 1,1 & 4,6 & 10,7 & 2,8 & 13,6 & 235 & 42,5 \\
\hline & 1,0 & 1,7 & 8,5 & 12,5 & 2,6 & 18,3 & 364 & 50,9 \\
\hline & 2,0 & 1,4 & 6,5 & 12,3 & 2,7 & 15,2 & 241 & 48,4 \\
\hline \multicolumn{2}{|c|}{ Equação Linear } & $\mathrm{ns}$ & $\mathrm{ns}$ & ns & ns & ns & ns & $\mathrm{ns}$ \\
\hline \multicolumn{2}{|c|}{ Equação Quadrática } & $\mathrm{ns}$ & $*$ & ns & ns & $\mathrm{ns}$ & $\mathrm{ns}$ & ns \\
\hline
\end{tabular}

* Significativo a p $\leq 0,05$, ns - não significativo

\section{CONCLUSÕES}

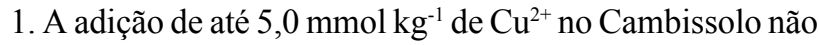
ocasiona sintomas de toxicidade no feijoeiro e o seu acúmulo na parte aérea é inferior ao nível tóxico. As concentrações de $\mathrm{Cu}$ na raiz são superiores, em cerca de 3 a 10 vezes, e proporcionais às doses do metal no solo.

2. O tecido da planta mais indicado para monitorar a contaminação do solo por $\mathrm{Cu}$ é a raiz, devido ao seu maior acúmulo.

3. Os teores de $\mathrm{Zn}$ na parte aérea e na raiz aumentaram com o incremento das doses do metal no solo. Até a dose de 2,0 $\mathrm{mmol} \mathrm{kg}{ }^{-1}$ de $\mathrm{Zn}$ não afetou o crescimento do feijoeiro.

4. As soluções $\mathrm{NH}_{4} \mathrm{OAc} 1,0 \mathrm{~mol} \mathrm{~L}^{-1} \mathrm{pH} \mathrm{4,8}$ e DTPA 5,0

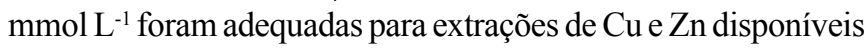
no solo.

5. A adição de $\mathrm{Cu}$ e $\mathrm{Zn}$ no solo alterou o teor de $\mathrm{K}$ na raiz do feijoeiro, mas os demais elementos ( $\mathrm{N}, \mathrm{P}, \mathrm{Ca}, \mathrm{Mg}, \mathrm{Mn}$ e B) da parte aérea e da raiz não foram alterados. 


\section{LITERATURA CITADA}

Adams, J.F.; Kissel, D.E. Zinc, copper and nickel availabilities as determined by soil solution and DTPA extraction of sludge amended soil. Communication in Soil Science and Plant Analysis, New York, v.20, p.139-158, 1989.

Alloway, B.J. Heavy metais in soils. New York: John Wiley \& Sons, 1993.339p.

Basta, N.T.; Tabatabai, M.A. Effect of cropping systems on adsorption of metals by soils: II. Effect of pH. Soil Science, Baltimor, v.156, p.195-204, 1992.

Beckett, P.H.T. The use of extractants in studies on trace metals in soil, sewage sludges and sludges-treated soils. Advances in Soil Science, New York, v.9, 143-176, 1989.

Deluisa, A.; Giandon, P.; Aichner, M.; Botolami, P.; Bruna, L.; Lupetti, A.; Nardelli, F.; Stringari, G. Copper pollution in Italian vineyard soils. Communication in Soil Science and Plant Analysis, New York, v.27, p.1537-1548, 1996.

Dudley, L.M.; McNeal, B.L.; Baham, J.E.; Coray, C.S.; Cheng, H.H. Characterization of soluble organic compounds and complexation of copper, nickel and zinc in extracts of sludge amended soils. Jornual of Environmental Quality, Madison, v.16,p.341-348,1987.

Emmerich, W.E.; Lund, L.J.; Page, A.L.; Chang, A.C. Movement of heavy metals in sewage sludge-treated soils. Jornual of Environmental Quality, Madison, v.11, p.174-178,1982.

Junqueira Neto, A. Micronutrientes na cultura do feijão. In.: Fancelli, A.L; Dourado Neto, D. (ed.) Tecnologia da produção do feijão irrigado, Piracicaba: USP. 1997. 158 p.

Lavado, R.S.; Porcelli, C.A.; Alvarez, R. Nutrients and heavy metal concentration and distribution in corn, soybean and wheat as affected by different tillage systems in the Argentine Pampas. Soil and Tillage Research, Amsterdam, v.62, p.55-60, 2001.
Mattos, M.S.; Miyazawa, M. Deslocamento de metais pesados no solo. Reunião Anual da Sociedade Brasileira de Química, Caxambu-MG, 1995.

Miyazawa, M.; Pavan, M.A.; Bloch, M.F.M. Determination of $\mathrm{Ca}, \mathrm{Mg}, \mathrm{K}, \mathrm{Mn}, \mathrm{Cu}, \mathrm{Zn}$ and $\mathrm{P}$ in coffee, soybean, corn, sunflower and pasture grass leaf tissues by a $\mathrm{HCl}$ extraction method. Communication in Soil Science and Plant Analysis, New York, v.15, p.141-147, 1984.

Pavan, M.A.; Chaves, J.C.D.; Kaiser, A.A.P.G. Acúmulo de cobre no solo em cafeeiros tratados com fungicidas cúpricos. Arquivo de Biologia Tecnologia, Curitiba, v.37, p.409-415, 1994.

Perdue, E.M.; Beck, K.C.; Reuter, J.H. Organic complexes of iron and aluminum in natural water. Nature, London, v. 260, p.418-422, 1976.

Pohlman, A.A.; McColl, J.G. Soluble organics from forest litter and their role in metal dissolution. Soil Science Society of America Journal, Madison, v.52, p.265-271, 1988.

Reddy, K.J.; Wang, L.; Gloss, S.P. Solubility and mobility of copper, zinc and lead in acidic environments. Plant and Soil, Dordrecht, v.171; p.53-58, 1995.

SAS Institute, SAS/STAT, User's guide. Version 6, 4.ed. Cary, 1989. v.2. 846p.

Sloan, J.J.; Dowdy, R.H.; Dolan, M.S.; Linden, D.R. Long term effects of biosolids applications on heavy metal bioavailability in agricultural soils. Journal of Environmental Quality, Madison, v.26, p.966-974, 1997.

Souza, M.L.P.; Andreoli, C. V., Amarai, M. B; Domaszak, S. C. Levantamento preliminar dos teores de metais pesados em alguns solos do Paraná, Revista Técnica da SANEPAR, Curitiba, v.5, p.68-75, 1996. 